\title{
The Pattern of Sale and Use of Non-Steroidal Anti- Inflammatory Drugs in Rural and Urban Centres in Nigeria
}

\author{
OS Awofisayo ${ }^{*}$, OA Awofisayo ${ }^{2}$, II Iferi ${ }^{1}$ and OE Akpan ${ }^{3}$ \\ ${ }^{1}$ Department of Clinical Pharmacy and Biopharmacy, ${ }^{2}$ Department of Pharmaceutical and Medicinal Chemistry, \\ Faculty of Pharmacy, University of Uyo, Nigeria. ${ }^{3}$ JDJIDE Pharma Limited, Ikot Ekpene, Nigeria.
}

\begin{abstract}
Purpose: The widespread use of non-steroidal anti-inflammatory drugs (NSAID) has meant that the adverse effects of these relatively safe drugs have become increasingly prevalent. This work examines the pattern of sale and use of NSAIDs as to call for caution in cases of misuse that may lead to renal, gastrointestinal and cardiac damage in users.

Methods: 56 drug outfit managers in patent medicine store, pharmacy, hospital drug unit and market centre visited in their outlets, were evaluated with respect to years of experience, educational level and registration status. 180 NSAIDs users were also assessed based on their perception and pattern of use of the drugs in view of their personally declared previously and diagnosed ailments.

Results: $86 \%$ of the drug outfit managers had less than tertiary education with $59 \%$ of the sampled outfits being unregistered and unlicensed. $74 \%$ of the sample population procured their NSAIDs from sources where adequate pharmaceutical care is unlikely to be available in an observed situation where $79 \%$ have clinical conditions likely to be worsened by NSAID misuse. $11.1 \%$ of the respondents who are categorized as geriatrics ingest NSAIDs daily while over $23 \%$ of this class require more than two different NSAIDs at a time.

Conclusion: Restriction in the sale, by way of reviewing the sale status, of NSAIDs will drastically reduce the rate at which the drugs are ingested. The possible gastrointestinal, renal and cardiac damage due to NSAID misuse requires evaluation so that the required level of caution can be exercised in the handling of the drugs.
\end{abstract}

Keywords: NSAIDs, Sales pattern, Misuse, Sale status, Restriction 


\section{INTRODUCTION}

Non steroidal anti-inflammatory drugs (NSAID) are medicaments with analgesic, antipyretic and anti-inflammatory effects ${ }^{1}$. Certain NSAIDs including ibuprofen and aspirin have become accepted as relatively safe and available over the counter thus encouraging self-medication among the Nigerian populace in the management of pains, fever and inflammation. The outcome of self-medication and possible adverse drug reactions (ADR) are dependent on the quality of drug information given by the drug suppliers and the extent of use. An evaluation of the pattern of use of NSAIDs against possible adverse drug reactions on the rural and urban dwellers in Nigeria is crucial ${ }^{2}$.

It has been reported that unauthorized handling of drugs and self-medication is on the increase worldwide with particular reference to Asia and Africa ${ }^{3}$. NSAIDs are generally indicated for the symptomatic relief of rheumatoid arthritis, osteoathritis, dysmenorrhoea, pyrexia postoperative pain and other inflammatory arthropathies hence many people with chronic pains consume the drugs $^{3-4}$.

NSAIDs are acids and are well absorbed from the stomach and intestinal mucosa. The drugs are usually highly bound to plasma albumin, so that their volume of distribution approximates to plasma volume ${ }^{5}$. This class of drugs is metabolised in the liver by oxidation and conjugation to inactive metabolites and excreted in urine or partially in bile. The metabolism of NSAIDs may be abnormal in certain disease states and accumulation may occur even with normal dosage. The main ADR associated with NSAIDs relates to gastrointestinal (GI) and renal effects ${ }^{6}$. These effects are dose dependent and in many cases pose serious risk of upper Gl bleeding, ulcers, intestinal perforation and death. An estimated $10-20$ NSAIDs associated upper GI adverse events resulting in 103,000 hospitalizations and 16,500 deaths per year in the United States have been reported ${ }^{7}$. NSAIDs have also been reported to be associated with a relatively high incidence of renal ADR. The mechanism of these renal $A D R$ is probably due to changes in renal haemodynamics through inhibition of prostaglandins. Analgesic nephropathy is less fashionable than it was 20 years ago since the dangers of analgesic mixtures became widely known and the sale of phenacetin, the most implicated drug, was banned in most countries ${ }^{8}$.

A review of the subject of NSAIDs induced renal damage and other assaulted organ is timely because of the possible extensive prescribing and misuse due to the over-thecounter status of the drug in developing countries.

The objective of this preliminary study was to assess NSAIDs availability, manner of combination for consumption and the knowledge of drug vendors and users in the circumstance that calls for caution in NSAIDs use $^{9}$

\section{METHOD}

The study area is made up of 3 senatorial districts namely; Eket, Uyo and Ikot Ekpene. A total of 7 pharmacy shops, 45 patent medicine shops, 3 General hospitals and 6 village market drug outlets were enlisted for the study. The design of the questionnaire was to obtain information on the pattern of NSAIDs use and evaluation of existing/potential risks to the internal organs. The questionnaire was divided into three sections $A, B$, and $C$. Section $A$ relates to information on the demographics of the respondents. Section B contains information on the rationale for the use of NSAIDs and the pattern of combination of the drugs. Section $C$ investigates the level of knowledge of the users about their drugs of choice and the perceptible present and potential risks attributable to NSAIDs among them. The questionnaires were administered to the end users through the drug outlet managers who were properly instructed to be able to assist their clients. The principal researcher collected the data with the help of 5 trained assistants. The data was analysed using Statistical Package for Social Sciences (SPSS) version 10. 
Table1: Demographics of drug outfit managers

\begin{tabular}{|c|c|c|c|c|c|c|c|}
\hline $\begin{array}{l}\text { Level of } \\
\text { Manager } \\
\text { In Charge }\end{array}$ & $\begin{array}{l}\text { Primary } \\
\text { Education }\end{array}$ & $\begin{array}{l}\text { Secondary } \\
\text { Education }\end{array}$ & $\begin{array}{l}\text { Tertiary } \\
\text { Education }\end{array}$ & $\begin{array}{l}\text { Informal } \\
\text { Training }\end{array}$ & Others & Total & $\%$ \\
\hline $\begin{array}{l}\text { Mean age } \\
\pm S D\end{array}$ & $28.3 \pm 7.8$ & $35.6 \pm 6.9$ & $45.2 \pm 7.9$ & $26.9 \pm 7.4$ & $42.5 \pm 5.4$ & - & - \\
\hline \multicolumn{8}{|l|}{$\begin{array}{l}\text { Experience } \\
\text { (years) }\end{array}$} \\
\hline$<5$ & 7 & 7 & 3 & 8 & 3 & 28 & 42.4 \\
\hline $5-9$ & 5 & 4 & 1 & 3 & 1 & 14 & 21.2 \\
\hline $10-14$ & 5 & 4 & 3 & 2 & 2 & 16 & 24.2 \\
\hline $15-20$ & 2 & 1 & 2 & - & 1 & 6 & 9.1 \\
\hline$>20$ & 1 & - & - & 1 & - & 2 & 3.0 \\
\hline $\begin{array}{l}\text { Registration } \\
\text { Status } \\
\text { (Number regd.) }\end{array}$ & -1 & 3 & 6 & 3 & 1 & 13 & 23.2 \\
\hline $\begin{array}{l}\text { Use of NSAIDs } \\
\text { require caution } \\
\text { (Agree) }\end{array}$ & - & - & 14 & 1 & -1 & 15 & 26.8 \\
\hline $\begin{array}{l}\text { Availability in } \\
\text { stock of at least }\end{array}$ & & & & & & & \\
\hline $\begin{array}{l}5 \text { different } \\
\text { NSAIDs }\end{array}$ & 6 & 12 & 18 & 13 & 6 & 55 & 98.6 \\
\hline $\begin{array}{l}\text { Muliple NSAIDs } \\
\text { taken together } \\
\text { give better relief } \\
\text { (Agree) }\end{array}$ & 6 & 10 & 11 & 13 & 5 & 45 & 80.4 \\
\hline
\end{tabular}

Table 2: The pattern of consumption of NSAID by the respondents showing percentages for adult male and female ( $<60$ years) and geriatrics both sexes combined ( $>60$ years)

\begin{tabular}{|c|c|c|c|c|}
\hline $\begin{array}{l}\text { Parameters for } \\
\text { ingestion }\end{array}$ & Male $<60 \mathrm{yr}$ & Female $<60 \mathrm{yr}$ & $\begin{array}{l}\text { Male + Female }>60 \\
\text { yr }\end{array}$ & Total (\%) \\
\hline Daily & $13(7.2 \%)$ & $18(10 \%)$ & $20(11.1 \%)$ & $28.3 \%$ \\
\hline Weekly & $9(5 \%))$ & $5(2.80 \%)$ & $12(6.70 \%)$ & $14.5 \%$ \\
\hline Occasional & $23(12.8 \%)$ & $37(20.6 \%)$ & $10(5.6 \%)$ & $39.0 \%$ \\
\hline $\begin{array}{l}\text { Single NSAID } \\
\text { per time }\end{array}$ & $27(15 \%)$ & $46(25.6 \%)$ & $7(3.9 \%)$ & $44.5 \%$ \\
\hline $\begin{array}{l}\text { Multiple NSAID } \\
\text { per time }\end{array}$ & $29(16.1 \%)$ & $32(17.8 \%)$ & $34(18.95 \%)$ & $52.9 \%$ \\
\hline
\end{tabular}




\section{RESULTS}

One hundred and eighty respondents returned the questionnaire (100 females and 80 males). The respondents ingested NSAIDs daily, weekly or as the need arise with over $28.3 \%$ of respondents ingesting analgesics everyday (see Fig1). The pattern of use of multiple analgesics among the respondents revealed $52.9 \%$ taking more than one NSAIDs each time (see Table 3 ). Out of $27 \%$ of the study population who were above 60 years (geriatrics), over $47.6 \%$ ingest NSAIDs daily while $80.9 \%$ require more than two NSAIDs at a time. Considering the 66 outlets in the study area, fifty three $(80.3 \%)$ were unregistered and unlicensed while thirteen (19.7\%) were licensed by the Pharmacists Council of Nigeria. Twenty $(30.3 \%)$ of the drug handlers had primary education, sixteen $(24.2 \%)$ had secondary education, fifteen $(22.7 \%)$ had tertiary education while five $(7.6 \%)$ were auxiliary nurses who had one form of informal training or the other (Table 1). The preferential place of purchase of drugs by the respondents is outlined in Fig 1. The respondents gave a searchlight to their known medically diagnosed conditions for which cautionary use of NSAIDs is required. (Fig 2).

\section{DISCUSSION}

Pharmacists are usually the custodian of drugs and are charged with the responsibilities of delivering safe and efficacious medicines to the public ${ }^{10}$. In developing countries, traders perceive drugs as items of trade. In Nigeria, a country where the ratio of pharmacist to non-pharmacist in an urban environment and commercial centre, like Lagos is approximately 1:3, NSAIDs are sold or ingested without the required level of caution. These unregistered drug outlets, usually manned by traders, are located virtually in every street of urban centers in Nigeria.

Evaluation of drug use revealed that there was a great deal of drug misuse ranging from sub - therapeutic dosing, wrong indication and irrational combination of drugs, even in high doses.
This study revealed that self-medication was prevalent in the research environment, as over $93 \%$ of the respondents did not see a doctor before obtaining a pain reliever. The fact that NSAIDs is a subject of such unrestricted access is synonymous with them being regarded as a mere commodity or a supermarket item. A large proportion of the respondents (52.9\%) also use and believe that pain relief is achieved faster when two or more NSAIDs are ingested- an impression that could have originated from a wrong counsel. Some ailments are caused and can be complicated by overuse of NSAIDs therefore the drugs are advisably employed with caution in such ailments. The high rate of self-acknowledged ailment in the study population could be suggestive of the result of NSAIDs misuse which is on going as $28.3 \%$ of the respondents still employ NSAIDs on a daily basis. This high percentage of the population may benefit from restricted access to NSAIDs than the temporary relief that is achievable from their drug misuse. The right kind of counsel for effective drug use can be available in an approved drug outfit i.e. pharmacies and hospitals; the respondents in the study however prefer buying their NSAIDs from other unauthorized places. The fact that about $45 \%$ of handlers have less than secondary school education portrays the quality of drug information and counsel buyers get. In fact the traders may compel the buyers to buy more to maximize gains oblivious of the associated ADR.

NSAIDs inhibit prostaglandin synthesis causing unopposed renal arteriolar constriction leading to renal insufficiency ${ }^{11}$. In advanced age, the effect of NSAIDs is higher and incidentally, this is the age when NSAIDs were mostly desired. Different drugs have been implicated in causing renal insufficiency with indomethacin cited most commonly, perhaps owing to the greater use. The respondents indicated combining indomethacin with other NSAIDs. The renal effect of such unchecked usage as a result of prostaglandin inhibition also leads subsequently to inhibition of renin. The induced hyporeninaemic hypoaldosteronism 
precipitates hyperkalaemia. The use of drugs such as aspirin and indomethacin has been recognized to cause renal papillary necrosis, shortest period of time; a practice that this study shows is not often followed.

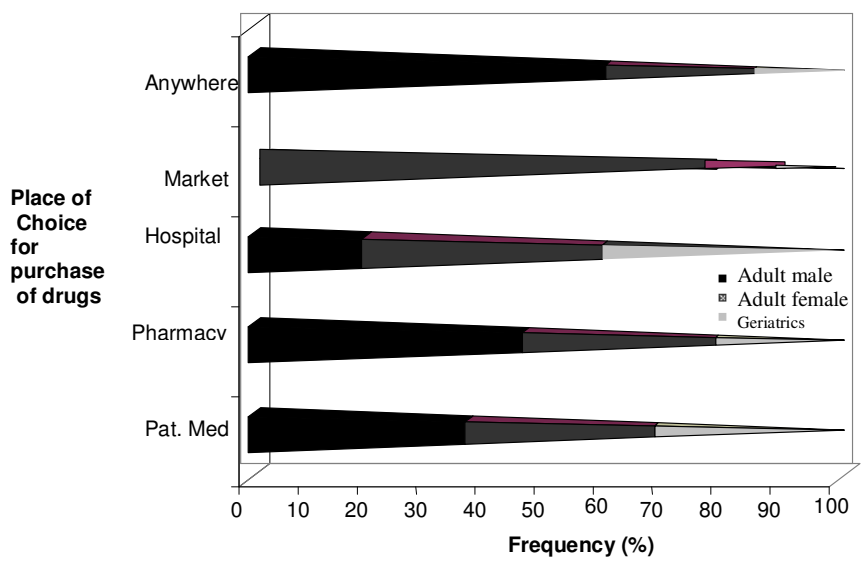

Fig 1: Analysis of preferential place of procuring NSAID among adult males (-), adult females ( $\square$ ) and geriatrics $(\varpi)$ in the population

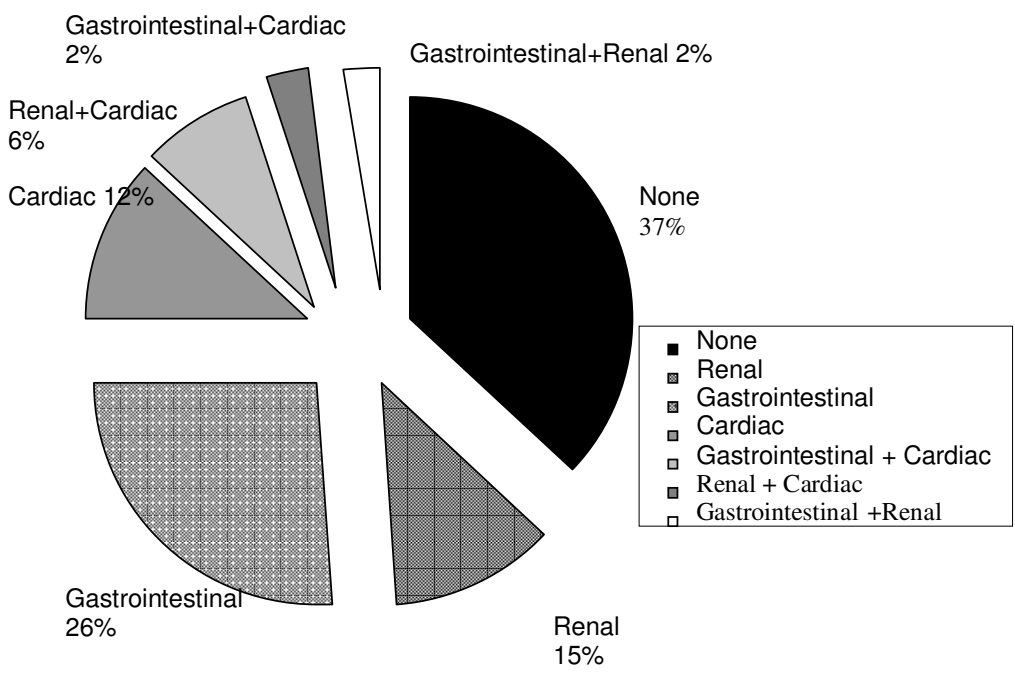

Fig 2: Personal declaration of previously diagnosed ailments by respondents

acute interstitial nephritis and other nephritic syndrome ${ }^{9}$.

The risk of ulceration increases with duration of use of NSAID and with higher doses. In attempting to reduce the GI ADR, it is prudent to use the smallest effective dose for the

\section{CONCLUSION}

The study revealed that there is no significant difference in the distribution of female to male ratio that employs NSAID on a daily, weekly or occasional basis (Fig 2). It thus means that NSAID are "household" in nature. From this 
study, epidemiologic research is needed on the factors that predispose persons to heavy use and misuse of NSAID. Research is also expedient on factors that may predispose users of NSAID to renal and GI injury.

\section{ACKNOWLEDGMENT}

The authors are grateful to JDJIDE Pharma Limited for financial support.

\section{REFERENCES}

1. Hang JQ, Sridhurshunt $R H$. Role of helicobacter pylori infection and non-steroidal anti-inflammatory drugs in peptic ulcer disease; a meta-analysis. Lancet 2000; 35914-22

2. Eniojukan JF, Aina BA, Alo AA. Drug abuse and selfmedication scenario in Nigeria. Nig $J$ Pharm 2000; 31:42-48

3. Carmichael J, Shankel SW. Effects of non-steroidal anti-inflammatory drugs on prostaglandins and renal function. Am J Med 1995; 78: 992-1000

4. Koch M, Dezi A, Ferrario F, Capurso L. Prevention of non-steroidal anti-inflammatory drug induced gastrointestinal mucosa reaction: a metaanalysis of randomized controlled trials. Arch Intern Med 1996; 156: 2321-2332.

5. Matzke GR, Feyc RE. Drug administration in patients with renal insufficiency; minimizing renal and extra renal toxicity. Drug Safety 1997;

6. Fillastre JP, Godin M. Drug induced nephropathies. Oxford Medical Publications 1997 pp 26452658.

7. Feenstra J, Heerdrink DE, Grobbee DE, Stricker BE. Association of non-steroidal anti-inflammatory drugs with relapsing heart failure : the Rotteerdam study. Arch Intern Med 2002; 162: 235-270.

8. Matthew TH. Drug-induced renal disease. Med J Aust 1992; 156:724-728.

9. Chroudhury D, Limed Z. Drug induced nephrotoxicity. Med Clin N Am 1997;81:705-717

10. Dde Broe ME, Elseviers MM. Analgesic nephropathy. N Engl J Med 1998; 338:446-452.

11. Maxwell SR, Webb D. COX-2 Selective inhibitorimportant lessons learned. Lancet 2005; 365(9458):449-451. 